Projections • 15. Practices of Health in Unruly Environments

\title{
Planning for Youth
}

Emotional Health in Unruly

Environments: Bringing a

Trauma Informed

Community Building Lens

to Therapeutic Planning

Jason Reece ${ }^{1}$

${ }^{1}$ City \& Regional Planning, Knowlton School of Architecture, The Ohio State University

MIT Press

Published on: Oct 26, 2020

DOI: $\underline{\text { https://doi.org/10.1162/00c13b77.29ae0baa }}$

License: Creative Commons Attribution 4.0 International License (CC-BY 4.0). 


\section{ABSTRACT}

Planning in the context of emotion is an important but underemphasized aspect of planning practice. Planning literature has traditionally viewed issues of trauma through the lens of therapeutic planning. Two strands of scholarship emerging from the field of public health can enhance our understanding of planning for the emotional health of youth. Trauma Informed Community Building (TICB) focuses on community building strategies that counteract contemporary trauma found in challenging environments. Scholarship documenting the impact of youth trauma, referred to as Adverse Childhood Experience (ACE's) emphasizes the need to support emotional health for youth. The paper presents a case study of the I Am My Brother's Keeper (I Am MBK) program, implemented in Columbus, $\mathrm{OH}$, as a model of trauma informed youth community development. I Am MBK illustrates the importance of supporting the emotional health of youth as a form of planning for emotion. Findings from the I Am MBK case illustrate how trauma informed practice can strengthen our existing concept of therapeutic planning, by supporting the emotional health of youth through empowerment, radical acceptance, creation of safe spaces, advocacy, relationship building, mind/body practices and experiential learning. The I Am MBK case improved the emotional health of youth but could not counteract other systemic or structural policy challenges in the community. The case demonstrates the importance of aligning planning for emotional health with reforming systems and structures in alignment with Schweitzer's three obligations of restorative healing.

\section{Introduction}

The I Am My Brothers Keeper (I Am MBK) program was intensive. Youth would devote an entire Saturday, almost every Saturday of the year to the program. This commitment was in addition to weekly after school sessions, and weekly home visits by the community engagement team. Many of the youth in I Am MBK were kids who were pushed out of other traditional community programs. They were deemed to be behaviorally problematic or their participation was too inconsistent. As a program evaluator I always questioned why youth in I Am MBK were willing to stay so engaged. As we listened to boys in the program, it was apparent that they were engaged because I Am MBK wasn't just another community engagement or program. The staff had created a sacred community space, a safe space where boys who faced numerous challenges, could feel safe, protected and be kids. It was a space where they could be vulnerable, and process trauma they had experienced. As one of the youth described 
"When I am here, it's like a home, because when I am at school, I have my doubts, because people are saying stuff about me, doing stuff to me, I am in bad company, but here I feel safe, when I'm here, I feel like it's my family."

Planning literature has traditionally viewed issues of emotion and trauma through the lens of therapeutic planning (Sandercock, 2000 \& 2004). Emerging from the field of public health, Trauma Informed Community Building (TICB) focuses on community development strategies that acknowledge and address the source of contemporary environmental trauma (Weinstein et al. 2014). TICB is a form of community planning that seeks to empower, restore hope and foster a sense of agency, while addressing critical community stressors.

Therapeutic planning has primarily focused on community trauma which is often historical or the direct result of discriminatory institutional practices. Therapeutic planning in practice includes community engagement and community building processes to engage historical discrimination within communities. Most therapeutic planning case studies have emphasized work within historically marginalized indigenous communities. The model has seen less application in the context of nonindigenous communities. Therapeutic planning is still an emergent domain of scholarship and practice requiring further application and investigation and "testing its possibilities" (Erfan, 2017, pg. 47).

Therapeutic planning has also been less attentive to engaging ongoing trauma which is influenced by environmental conditions within neighborhoods (e.g. gun violence or housing insecurity) and how these factors can impact community building activities. This paper seeks to integrate emergent concepts from TICB and Adverse Childhood Experience (ACE) scholarship to enrich our models for planning to support emotional health in high stress environments.

The paper presents a case study of the I Am My Brother's Keeper (I Am MBK) program, implemented on the South Side of Columbus, $\mathrm{OH}$, as a model of trauma informed community development. I Am MBK utilized a trauma informed approach to support marginalized boys of color through intensive community building activities. The program worked with a cohort of highly at-risk youth and their families on the South Side. The I Am MBK case study presents the impacts of the TICB model. More importantly, the case study creates an opportunity to understand how aspects of TICB could enrich our conceptualization of planning for the emotional health of youth in challenging environments. 
Utilizing the I Am MBK case study, the paper seeks to explore two primary questions. How was TICB integrated into practice and how did it support health outcomes for youth, if at all? Second, what are the limitations of the TICB model and is it a sustainable approach to planning for emotion in unruly environments? The article closes with a discussion of the potential contributions and limitations of TICB in engaging historical, structural (systems level) and individual trauma into youth community building.

\section{Acknowledging emotion in planning: Evolving theories of therapeutic planning, Trauma Informed Community Building and adverse childhood experience}

Planning scholarship has engaged topics of emotion and mental health for a half century. Collective community trauma has been explored in planning literature as a byproduct of the psychological impacts of urban renewal (Marris 1974). The destruction produced by urban renewal in Boston's West End neighborhood produced scholarship from planners, social scientists and psychiatrists connecting the acute stress of displacement to mental health (Ramsden and Smith, 2017). Direct engagement of emotion and historical trauma would be further explored in the context of communicative planning (Forester, 1999).

As articulated by Howell Baum in 2015 and more recently by Ward Lyles and Stacey Swearingen White, planning has struggled to engage issues of emotion (Baum 2015 \& Lyles and Swearingen White 2019). Baum notes that when compared to other social sciences, planning scholarship is not as robust in engaging topics of emotion. Baum acknowledges the persistence of rationality as a dominant paradigm which undermines the field's ability to engage topics of emotion. Lyles and Swearingen White have explored the stigmatization of emotion and the emotional paradox which can undermine the ability to sustain effective engagement.

Therapeutic planning is as a form of communicative planning which directly engages the emotional aspects of conflict in the multi-cultural city (Sandercock, 2000). Leonie Sandercock articulated therapeutic planning as a dialogical approach between antagonistic parties, emphasizing mediation and negotiation. Therapeutic planning directly engages past historical conflicts or traumas. Therapeutic planning as defined by Sandercock is distinctly different from forms of "therapy" labeled as nonparticipatory in Arnstein's a Ladder of Citizen Participation (Arnstein, 1969). 
Planning can act as "a therapeutic process in which the space is created for speaking the unspeakable, for talk of fear and loathing, as well as of hope and transformation" (Sandercock, 2000, pg. 24). Sandercock challenges the emphasis on planning as simply regulatory practice, proposing that planning should be "as alert to the emotional economies of cities as it is to the political economies" (Sandercock, 2004, pg. 113). Therapeutic planning seeks to produce a social transformation which can produce "permanent shifts in values and institutions" (Sandercock, 2004, pg. 139). Therapeutic planning requires strong communication skills, openness, the establishment of safe spaces where community members views will not be rejected or dismissed and crosscultural understanding (Sandercock, 2000).

Therapeutic planning has been used in conjunction with film production as a form of planning engagement which facilitates a therapeutic environment (Sandercock \& Attila, 2014). Therapeutic planning efforts have included "Deep Democracy" sessions with first nations communities in Canada (Erfan 2013 \& Erfan 2017). Evaluation of these sessions would find "modest but promising" benefits from the application of a therapeutic planning model within the community (Erfan, 2017). Therapeutic planning can be inaccurately viewed as too emotional or not rational, thus it is in conflict with positivist perspectives of planning practice (Erfan, 2017).

In Restorative planning ethics: The therapeutic imagination and planning in public institutions, Lisa Schweitzer acknowledges the implied and problematic (counselorpatient) dynamic in the language of therapeutic planning and suggests an approach that is framed as "restorative healing" (Schweitzer, 2014). Schweitzer argues that planners have three professional or moral obligations within the restorative healing approach. First, to explore and build collective understanding around the harms experienced by communities, and their remedies. Second, to seek institutional reform within government agencies that both acknowledge the harms inflicted upon communities and seek to support remedies. Third, to transform the broader political community to align with the needs of those communities which have been harmed.

\section{The development of Trauma Informed Community Building}

Trauma-informed practices are strategies to mitigate the impacts of trauma and foster resiliency. Trauma-informed practices have long been embraced in fields such as public health, social work and education (Herrenkohl et al 2019; Mersky et al 2019). Research suggests that targeting trauma-informed programming at the most at-risk populations (through race and location) will be more effective in reducing risks associated with trauma and chronic stress (Whiteside-Mansell et al. 2019). 
The emerging model of Trauma Informed Community Building (TICB) may provide a way to meet the needs of communities experiencing high rates of contemporary trauma and chronic stress. TICB seeks to support community building efforts that stabilize and empower residents while addressing long term community stressors. TICB seeks to counter trauma stemming "violence, poverty, homelessness, social isolation, and racism" (University of Wisconsin, 2019).

Trauma Informed Community Building (TICB) emerged through the intersection of community development and public health practice. TICB was created through collaboration between a traditional community development corporation (BRIDGE) and the Health Equity Institute in San Francisco. TICB was implemented as part of the redevelopment efforts for the Potrero Terrace public housing site in San Francisco (Gordon et al. 2015). TICB would also be implemented in multiple community violence prevention efforts in Florida and in community building activities in Pittsburgh (University of Wisconsin, 2019).

The TICB model was developed in response to the challenges to traditional neighborhood planning in high trauma communities. The extensive "depth and breadth" of community needs in high trauma communities can overwhelm organizations and individual programs. Residents are often in crisis mode, which does not allow them to focus beyond their immediate needs and undermines the capacity to plan or envision the future. Legacies of community disempowerment, discrimination and limited community resources foster distrust and apathy (Weinstein et al. 2014). Trauma and chronic stress leave residents in "survival mode" creating an impediment for communities to envision and plan for the future (Neufeld 2016, pg. 1).

TICB begins with an acknowledgement of past trauma and the harm done to the community. This acknowledgement is critical to begin processes of healing (Falkenberger et al. 2019). TICB is focused on four broad principles (do no harm, radical acceptance, empowerment and reflective practice). "Do no harm" guides practitioners to avoid unintentionally inflicting additional emotional harm upon residents. Practicing the principle of "do no harm" could include greater sensitivity in community engagement and program delivery, or assuring planning processes are not raising expectations about actions that are not likely to be implemented.

Practices of "radical acceptance" integrate forms of cultural humility in community interactions. Radical acceptance requires practitioners to alter practices (such as models of engagement) to meet the needs of the community or to create safe spaces where all community voices are accepted. Radical acceptance requires an open- 
minded embrace of community norms even when those norms conflict with traditional practice. Empowerment strategies emphasize community self-determination and leadership development. Reflective practices encourage practitioners to consistently reflect and modify strategies as community needs shift.

From these four principles TICB adopts strategies that operate at the individual, interpersonal, community and systems levels. These strategies mirror the primary domains of the socio-ecological model in public health (Center for Disease Control, 2020). Strategies range from not overpromising and being consistent when working with residents, to supporting community leadership development or integration of community voices into systems, service delivery and community investments. Strategies also focus on addressing the most influential community stressors and seek to de-escalate stress within neighborhoods. The TICB model seeks to foster enhancement in community "readiness" for community building and community development. Community readiness is supported by the de-escalation of neighborhood stressor, improving social cohesion and increasing social capital to support resiliency (BRIDGE, 2014).

\section{Planning for emotion as a health intervention: Understanding the corrosive inf luence of trauma and chronic stress on health}

TICB aligns with an expanding body of literature that has demonstrated the harms of trauma and chronic stress on health. The human stress response system has evolved to respond via fight or flight to episodic stressors. Unrelenting forms of chronic stress (e.g. stress produced from poverty, hunger, homelessness) do not allow the chemical and physical responses to stressors to diminish, producing detrimental impacts to the body. Prolonged inflammation, altered metabolism and suppressed immune response are just a few of the potential outcomes of chronic stress (Russell \& Lightman, 2019).

Chronic stress can also negatively impact brain function and increase long term susceptibility to mental illness (Chetty et al. 2014 and Marin et al. 2011). Long term detrimental health behaviors, such as substance abuse, can also emerge in high chronic stress communities as a short term response to alleviate chronic stress (Jackson et al. 2010). Incidents of trauma are extreme stress events which also can contribute to long term physical and mental health risks (Van Der Kolk, 2003).

Trauma events and chronic stress are most damaging during childhood and adolescence. Trauma incidents which are often identified as adverse childhood experiences (ACEs) include a range of early life experiences such as exposure to 
violence, abuse, household dysfunction, incarceration of loved ones or exposure to certain environmental factors (American Academy of Pediatrics, 2014). ACEs have been linked to increased risk of many adult health challenges, including cardiovascular disease, obesity, adult sleep deprivation, substance abuse, depression, violent behavior and suicide (Stern \& Thayer 2019, Gentner \& Leppert 2019, Yang \& Hedeker 2019, Sullivan et al. 2019 \& Hughes et al. 2017).

ACEs are cumulative health risk factors, with risk levels increasing for each ACE experienced. In comparison to individuals who had not experienced an ACE, individuals with multiple ACE exposures were more likely to have four or more negative health outcomes (Mersky et al 2013). Adults who have had six or more ACESs have a 20-year life expectancy difference when compared to adults who have not experienced an ACE (Brown et al. 2009). ACEs have also disrupted sleep patterns for individuals more than fifty years after experience childhood trauma events (Sullivan, 2013). The impact of ACEs is heightened when combined with other severe forms of socio-economic deprivation (Morris et al. 2019).

Exposure to chronic stress and trauma varies by population and geography. Twenty two percent of children in the United States have had two or more Adverse Childhood Experiences. Multiple ACEs are far more prevalent among children of color, with 34\% of African American and 37\% of Native American children experiencing two or more Adverse Childhood Experiences (Annie E. Casey Foundation, 2018).

Forms of trauma are more prevalent in neighborhoods with more chronic stressors, such as poverty, violence, incarceration, housing instability or food insecurity. Discrimination and patterns of racial and economic segregation contribute to higher exposure to chronic stressors or forms of trauma for certain populations, such as urban children of color (Morsy and Rothstein 2019). Children of color are more likely to be living in lower opportunity neighborhoods, with more chronic stressors and fewer resources (Acevedo-Garcia et al. 2014). High trauma environments face a multitude of reinforcing community stressors ranging from disinvestment and detrimental environmental conditions and a lack of trust influenced by historic discrimination and inconsistent services (Falkenburger et al. 2018).

\section{Intersecting bodies of literature: Planning for youth emotional and physical health}

Emerging literature on the effects of toxic stress and trauma on psychological and physical health bring attention to the ongoing need for planning to robustly engage 
emotion. TICB is a recent addition to our models for planning in the context of a community's emotional health. While both therapeutic planning and TICB engage issues of emotion and trauma, the models are distinct in their approach and focus (Table 1). Models of therapeutic planning have traditionally focused on trauma inflicted by structural forms of discrimination and have had an emphasis on historical trauma. TICB has limited focus on historical trauma and places emphasis on engaging contemporary trauma facing residents on an ongoing basis, but TICB has not focused attention on the unique needs of youth.

\begin{tabular}{|c|c|c|}
\hline $\begin{array}{l}\text { Table } 1 \\
\text { Comparing characteristics of } \\
\text { Therapeutic Planning with } \\
\text { Trauma Informed Community } \\
\text { Building. }\end{array}$ & $\begin{array}{l}\text { Therapeutic Planning } \\
\text { (Sandercock 2000; Sandercock } \\
\text { 2004; Sandercock and Attila } \\
\text { 2014; Erfan, 2017) }\end{array}$ & $\begin{array}{l}\text { Trauma Informed } \\
\text { Community Building } \\
\text { (Weinstein et al 2014; } \\
\text { Falkenburger et al. 2018) }\end{array}$ \\
\hline Origin or Early Application & $\begin{array}{l}\text { Early application in the context } \\
\text { of projects with indigenous } \\
\text { populations as a form of } \\
\text { decolonizing planning. }\end{array}$ & $\begin{array}{l}\text { Application in planning process } \\
\text { for community's with high } \\
\text { degree of trauma and } \\
\text { undergoing redevelopment of } \\
\text { public housing site. }\end{array}$ \\
\hline Temporal Focus & $\begin{array}{l}\text { Historical or contemporary } \\
\text { trauma, most cases have } \\
\text { focused on historical trauma. }\end{array}$ & $\begin{array}{l}\text { Stronger focus on } \\
\text { contemporary sources of } \\
\text { trauma (and environmental } \\
\text { trauma - e.g. environmental } \\
\text { conditions fostering trauma). }\end{array}$ \\
\hline Theory of Change & $\begin{array}{l}\text { Creation of a "dialogical space" } \\
\text { in which past traumas or } \\
\text { injustices can be confronted, to } \\
\text { foster healing. Creating a space } \\
\text { for hope and social } \\
\text { transformation. }\end{array}$ & $\begin{array}{l}\text { Goal of integrating trauma } \\
\text { informed practice into ongoing } \\
\text { community planning to address } \\
\text { barriers to engagement and } \\
\text { foster readiness among } \\
\text { community. }\end{array}$ \\
\hline
\end{tabular}




\begin{tabular}{|c|c|c|}
\hline General Principles & $\begin{array}{l}\text { Safe space created where all } \\
\text { voices are values, embraced } \\
\text { and not dismissed. Allowing } \\
\text { direct confrontation of past } \\
\text { trauma and relationship to } \\
\text { present conditions. Process of } \\
\text { navigating conflicts in diverse } \\
\text { multi-cultural shared spaces. }\end{array}$ & $\begin{array}{l}\text { Avoid triggering past trauma } \\
\text { (do not harm). } \\
\text { Foster safe spaces and practice } \\
\text { radical acceptance. } \\
\text { Emphasis on empowerment and } \\
\text { leadership development. } \\
\text { Iterative process which requires } \\
\text { ongoing reflection and change } \\
\text { in strategy based on community } \\
\text { needs. }\end{array}$ \\
\hline Characteristics for Planners & $\begin{array}{l}\text { Strong relationship building } \\
\text { and trust building. Strong } \\
\text { interpersonal and facilitation } \\
\text { skills. Active listening skills. }\end{array}$ & $\begin{array}{l}\text { Strong relational skills and } \\
\text { practicing cultural humility. } \\
\text { Ability to be deeply reflective } \\
\text { and introspective. }\end{array}$ \\
\hline Structure of Engagement & $\begin{array}{l}\text { Community based action } \\
\text { research or forms of Direct } \\
\text { Democracy. }\end{array}$ & $\begin{array}{l}\text { Reforms to ongoing community } \\
\text { development practice and } \\
\text { specialized on-going } \\
\text { programming (e.g. leadership } \\
\text { development). }\end{array}$ \\
\hline
\end{tabular}

Research on the role of ACEs as a unique form of childhood trauma suggests that trauma informed strategies should be particularly attentive to the experience of youth. The body of literature emerging from the field of public health and child development speaks to the powerful impact adverse childhood experiences have on individual and community wellbeing. The intersection of ACE, TICB and therapeutic planning allows engagement of both historical, structural and contemporary personal trauma to be acknowledged in our community building processes, while bringing more focus and actions to address the unique influence of trauma on youth. Intersecting these three bodies of literature provides an opportunity to present a more holistic view on planning for the emotional needs of youth in challenging environments. The following case study presents an illustrative example of the benefits of intersecting these three bodies of literature to support the mental and physical health needs of youth. 


\section{Case background and setting: The South Side as an unruly environment}

I Am My Brother's Keeper was developed in 2014 and sought to foster relationship building, resilience and a holistic support system for boys of color on the South Side of Columbus, OH. Launched by Franklin County's Department of Job and Family Services, the program was a place-based community development effort focused on African American boys age 8 to 17. The program began with a cohort of 40 boys, eventually expanding to 142 participants enrolled throughout the program's implementation. All youth participants lived in households earning less than $200 \%$ of the poverty rate.

I Am MBK utilized various evidence-based strategies in its design, including embracing trauma-informed practices for youth, asset-based development and working within a two-generation model, which entails working with youth and their broader family. The program design was particularly attentive to supporting youth who had experienced adverse childhood experiences. The program focused on intensive relationship building activities, while offering weekly experiential programming centered on education, leadership development, wellness, arts and skill building.

The program focused on the South Side community in Columbus, OH. The South Side was selected due to the challenging conditions facing boys of color in the area and the existence of potential community assets which were to be leveraged for the program's implementation. The South Side community was undergoing intensive efforts to stabilize housing, led by the local children's hospital, in the aftermath of the 2008 housing crisis (Kelleher et al. 2018).

The local children's hospital (Nationwide Childrens Hospital) has implemented the Health Neighborhood Healthy Families (HNHF) program on the South Side for more than a decade. The program is one of the most extensive community development efforts led by a hospital in the nation. The ongoing South Side redevelopment efforts have led to a collaborative investment of more than $\$ 100$ million in support for various types of affordable housing in the past decade (Kelleher and Edgar, 2020). Much of the expansion of affordable housing in the neighborhood occurred near the end of the I Am MBK program. As discussed further in the case analysis, despite the gradual expansion of affordable housing in the neighborhood, most I Am MBK families were in unstable and unsafe housing.

I Am MBK was intended to leverage these ongoing community investments while engaging with multiple local organizational assets in the neighborhood. The program 
was first implemented through a local community development organization (Community Development for All People) and in its later phase the Columbus Urban League. The Kirwan Institute for the Study of Race \& Ethnicity at The Ohio State University acted as program evaluator, assisted with program design and provided program staff support. In total, more than fifteen organizations collaborated in some capacity with the I Am MBK initiative.

\section{Challenges and exposure to trauma}

At the time of the program's inception, African American boys on the South Side were facing extremely challenging conditions. More than 1 in 2 African American males age 6 to 14 in the neighborhood lived in poverty. (Reece, 2015). The primary census tracts served by the program were "lower opportunity" census tracts based on the Kirwan Institute's Neighborhood Opportunity Index (Figure 1).

\section{More Than My Brother's Keeper (MTMBK) - Neighborhoods Served}
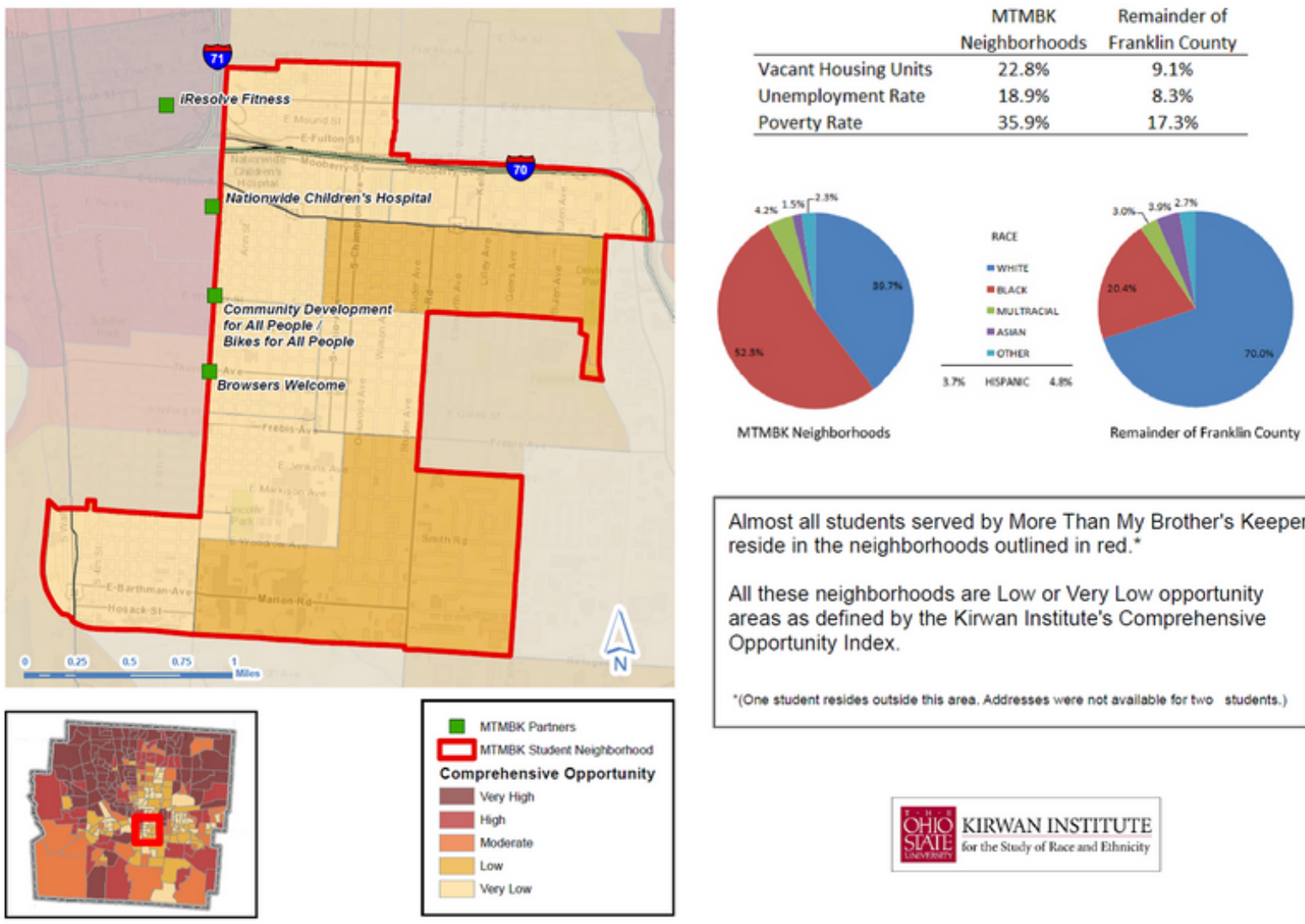

Almost all students served by More Than My Brother's Keeper reside in the neighborhoods outlined in red. *

All these neighborhoods are Low or Very Low opportunity areas as defined by the Kirwan Institute's Comprehensive Opportunity Index.

(One student resides outside this area. Addresses were not available for two students.)

Figure 1. Primary areas served by the MBK program and socio-economic conditions within service area. 
Abandoned properties and other forms of blight grew as a result of the national 2008 housing crisis, with the South Side becoming an epicenter of local foreclosure activity. In the primary census tracts served by the program, $22.8 \%$ of housing units were vacant when the program launched (Reece, 2015). The 'great recession' which followed the housing crisis, triggered extensive job losses in the South Side. In the primary census tracts served by the program, 1 in 3 residents lived in poverty and almost 1 in 5 people in the labor force were unemployed at the time the program began. African Americans made up 52\% of the residents in the areas served by the program (Figure 1).

These economic challenges were prevalent in the households of I Am MBK youth. The average I Am MBK family was a family of four (three children and one caregiver) with an annual household income of $\$ 14,400$. Challenges such as food insecurity, unsafe housing, housing instability, transportation barriers and lack of access to health care were systemic in the I Am MBK families (Reece, 2015). These daily stressors were a tremendous source of chronic stress and insecurity for youth.

In addition to the ongoing chronic stress associated with poverty, incidences of childhood trauma were prolific among youth in the program. All I Am MBK youth had experienced multiple ACEs and other forms of childhood trauma. As seen in Table 2, the most common ACEs were related to abuse, incarceration of a caregiver, homelessness and exposure to or victimization from violence. Behavioral challenges were also common with youth in the program, generally stemming from behaviors commonly associated with PTSD.

\section{Table 2}

Common forms of adverse childhood experiences (ACE's) experienced by I Am MBK youth 
The following are the commonly reported ACE's or forms of trauma experienced by participants. Staff estimated that most participants are at least six or more ACE's on the 10 point Ace scale. Some children would score an 8 or 9 on the 10 point ACE exam.

Abuse or Family Instability:

Exposure to domestic violence

Exposure to substance abuse/addiction

Abuse (Sexual and Physical)

Neglect (Parental Neglect or Abandonment)

Death of Parent or Caregiver

Incarceration (caregiver or close family member)

Siblings Placed in Foster Care

Violence/Safety:

Victimized by theft/robbery

Victimized by assault

Threatened with firearms/shots fired at youth

Witness to homicide

Witness to gun violence

Close family member victim of gun violence

Other Chronic Stressors:

Food Insecurity/Malnourishment

Forced Relocation/Eviction

Homelessness

Housing Unsafe or Infested with Pests

African American boys on the South Side were also deeply impacted by the stress of violence and fear of law enforcement violence. Analysis of the census tracts where program participants lived showed violent crime rates $280 \%$ higher than the city's overall violent crime rate (Reece, 2015). The service area for the program contained a concentration of gun violence incidents harming youth (Figure 2). I Am MBK youth 
were regularly exposed to violence, particularly gun violence which impacted their neighborhoods, friends and family members. Many of the youth had witnessed shootings or had lost family members to neighborhood violence.

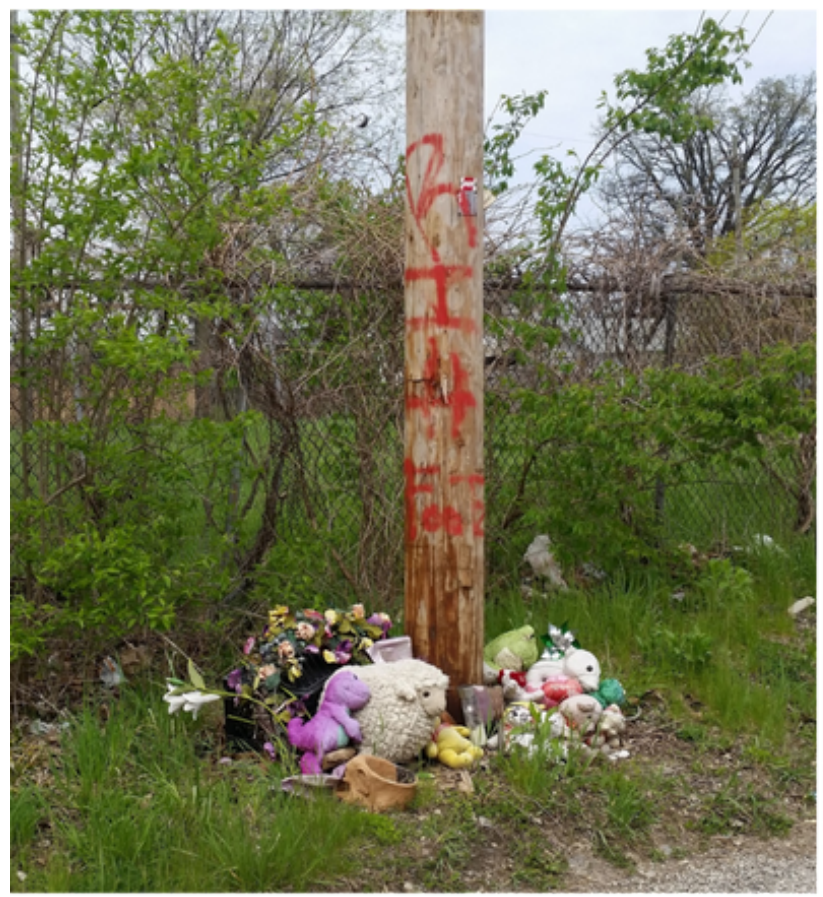

(Photo Above) Shooting/Homicide Memorial on Columbus's South Side
Youth Victims of Gun Violence in Columbus, 2012: Race
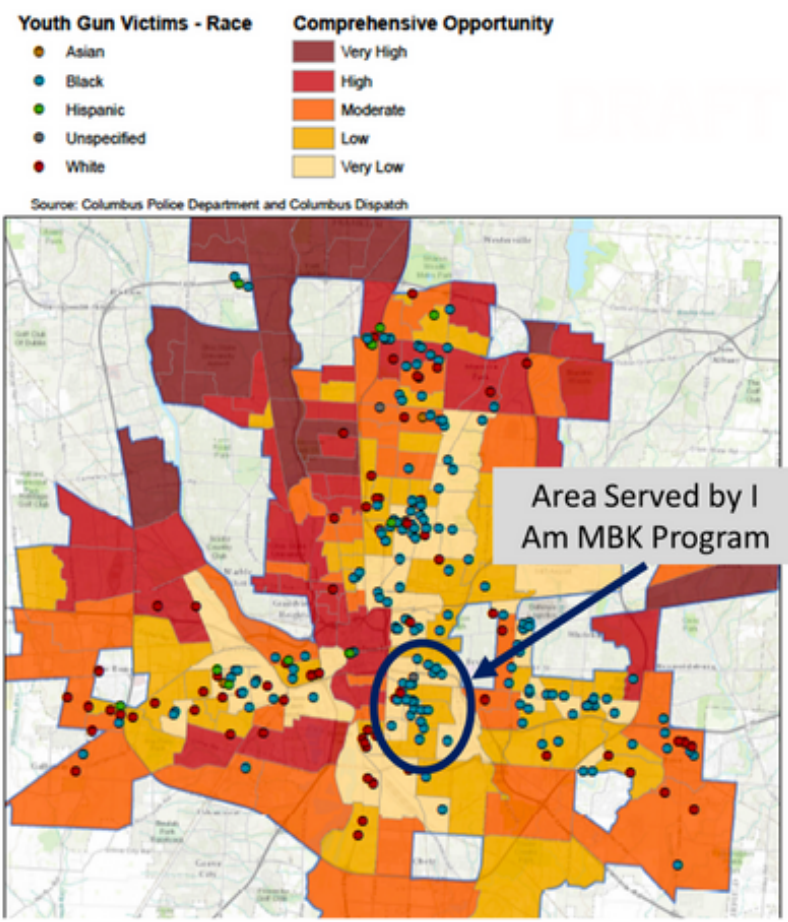

Figure 2. Visualization of Gun Violence on the South Side (Photo of Shooting/Homicide Memorial) and (Map of Youth Injured by Gun Violence in 2012)

These experiences align with research on the disparate exposure to forms of violence in communities of color. Studies focusing on inner city African American youth found that exposure to violence produced lower levels of emotional comfort, more risk behaviors and poorer education and employment outcomes (Griggs et al. 2019 \& McGee et al. 2017). Research suggests that exposure to gun violence is a unique trauma event which should be classified as an ACE (Rajan et al. 2019).

Neighborhood crime was not the only form of stress related to safety. Program participants also clearly identified feelings of fear and anxiety regarding local law enforcement. These concerns were heightened when a 15-year-old African American boy, who some of the program participants knew, was shot and killed by the Columbus Police Department (Reece, 2017). Law enforcement violence has been identified by the American Public Health Association as a detrimental social determinant of health, and 
research has directly found disparate impacts of law enforcement violence (and fear of law enforcement violence) facing African American males (Lee \& Robinson 2019).

\section{Case methods}

To explore the implementation of the TICB model, a single case study approach was utilized to analyze the experience of the I Am MBK program. Case study methodology is beneficial in exploring emergent theoretical constructs (Yin, 2014). Single case studies have been traditionally criticized as being non-generalizable and lacking analytical rigor, although these assumptions have been challenged in the literature (Flyvbjerg, 2006). Critical case selection can increase the potential analytical generalizability of a case (Flyberg 2006, Patton 2014).

Scott Campbell's working paper Case Studies in Planning: Comparative Advantages and the Problem of Generalization suggests that the case study method is uniquely beneficial in the context of city planning research (Campbell, 2003). Eugenie Birch's analysis of city planning case studies suggests that action-oriented cases (those focusing on the implications for practice), cases which emphasize place or a particular population and cases which revisit or reevaluate a phenomenon have had a substantial impact on planning practice and scholarship (Birch, 2012).

The rationale for selecting I Am MBK as a critical case includes the focus population (children of color who have exposure to trauma) and neighborhood (a neighborhood that has experienced historical and contemporary environmental trauma) and its implication for practice. Similar to applied examples of therapeutic planning, TICB has had limited implementation and I Am MBK is the only application of TICB focused explicitly on youth. Data for the case study is primarily qualitative, and specific measures (methods triangulation, prolonged engagement, persistent observation and member checking) were taken to enhance the reliability of case data (Denzin 1978, Lincoln \& Yuba 2005, 2006).

Several forms of data (participant observation, focus groups, interviews, secondary data on youth outcomes and parent surveys) have been triangulated to study the I Am MBK case. Table 3 provides details regarding each data source utilized for the case analysis. Data generated for the case were generated during program evaluation efforts (Reece \& Holley 2014, Reece 2015 and Reece \& Kenitzer 2017). A summary of data sources and analysis technique for each primary research question is provided in Table 4. 


\section{Table 3}

Detailed description of data sources utilized for case analysis.

Participant Observation: Participant observation activities included program activities, staff planning meetings, meetings with program funders and a review of video documentation of programming. More than 100 hours of observation activities occurred throughout the program's implementation from 2014 to 2017.

Focus Groups \& Interviews: Four focus groups were held with program staff between 2014 and 2017. In addition to focus groups, more than two dozen interviews were conducted with program staff and other program stakeholders between 2014 and 2017. Both focus groups and interviews were semi-structured. Follow up interviews were also conducted at the program's end to gain a reflective perspective from program staff.

Secondary Data for Youth Outcomes: Secondary data analysis focused on educational and disciplinary data for school and the DESSA (Devereux Students Strengths Assessment). School outcome data was generated form the Learning Circles data system for Franklin County Schools. Learning Circles is a universal data system allowing a standardized review of student outcomes across multiple academic and behavioral indicators. The DESSA is a commonly used evaluation tool to gauge social and emotional health for youth.

Educational outcomes for I Am MBK youth were analyzed in relation to a comparison group of youth. The comparison group included youth whose caregivers had enrolled them for the program but had chosen to not participate. Program staff still attempted to provide services and referrals to these youth, but these qualifying participant families chose not to participate in the primary I Am MBK program activities. While choosing not to participate in the program, the families had granted access to continue to analyze their children's educational data collected by the Columbus City school district.

Parent Surveys: Working in collaboration with program staff, parent surveys were conducted in 2015 and 2017. Parent surveys focused on parent perceptions of changes in behavior, academics, self-esteem and optimism for their children. Parent surveys were conducted with 27 MBK families in 2015 (representing 67\% of the program's active participants in 2015) and 35 MBK families in 2017 (representing 50\% of the program's active participants in 2017).

\section{Table 4}

Summary of data sources and analysis technique for each primary research question 


\begin{tabular}{|c|c|c|}
\hline $\begin{array}{l}\text { First, how was TICB integrated } \\
\text { into practice and how did it } \\
\text { support health outcomes for } \\
\text { youth, if at all? }\end{array}$ & $\begin{array}{l}\text { Parent survey data on youth } \\
\text { outcomes. } \\
\text { Secondary data on educational } \\
\text { and mental health outcomes for } \\
\text { youth. } \\
\text { Focus groups and interviews } \\
\text { data. }\end{array}$ & $\begin{array}{l}\text { Educational data outcomes } \\
\text { compared to a peer cohort } \\
\text { group that did not participate in } \\
\text { the program. } \\
\text { Thematic analysis of interview } \\
\text { and focus group transcripts and } \\
\text { participant observation notes. }\end{array}$ \\
\hline $\begin{array}{l}\text { What are the limitations of the } \\
\text { TICB model and is it a } \\
\text { sustainable approach to } \\
\text { planning in unruly } \\
\text { environments? }\end{array}$ & $\begin{array}{l}\text { Focus groups and interviews } \\
\text { data. Participant observation. }\end{array}$ & $\begin{array}{l}\text { Thematic analysis of interview } \\
\text { and focus group transcripts and } \\
\text { participant observation notes. }\end{array}$ \\
\hline
\end{tabular}

Parent surveys and youth behavioral health data were summarized and presented directly. Data on youth educational outcomes were compared to a peer cohort group of youth. Standard techniques of thematic analysis (based upon Bruan and Clarke's six phases of thematic analysis), were utilized to analyze all qualitative data produced from focus groups, interviews and the notes from participant observation (Braun \& Clarke, 2006). Thematic analysis produces a synthesis of major themes emerging from qualitative data generated for the project. Themes were generated first using inductive analysis (coding major themes without pre-conceived focus questions) and second using deductive analysis (coding based on the primary pre-conceived research questions). Qualitative data presented in the analysis section of this report represent primary themes identified through inductive and deductive coding of data.

My positionality in relation to this research included several potential conflicts of interest which required navigation. I supervised staff at the Kirwan Institute who made up a portion of the program staff. I also co-authored the funding proposal which launched the pilot program. I was a South Side resident during this time period, involved in several different education and community development projects, and youth in the program were my neighbors. From a personal vantage point, I also was cognizant of my own experience of childhood trauma and how this personal experience impacted my view of the program. My positionality in reference to this research has required intensive reflexive activity and efforts to avoid bias in my assessment of the project. Outside of adherence to rigorous data collection methods and internal reflections, I depended on a variety of external perspectives from program stakeholders in advising on the analysis and interpretation of the data. 


\section{Results}

\section{How was TICB integrated into practice?}

I Am MBK integrated trauma informed practices in alignment with the model of TICB. The TICB model does not prescribe particular actions, but proposes broad principles that must be adapted to the unique needs of the community. In practice, for the I Am MBK program, these strategies needed to be tailored to the focus population (boys of color). TICB was integrated into practice by utilizing the four primary principles of TICB (Weinstein et al. 2014).

Do No Harm: I Am MBK had to be very sensitive to avoid re-traumatizing youth and families in the community. Staff were very cognizant of potential trauma "triggers" which could exacerbate challenges facing youth and families. Addressing behavioral challenges involved actively practicing the principle of "do no harm." In engaging with most systems (education, social services etc.) youth behavior challenges or "acting out" were remedied through discipline and without recognition that behaviors are a byproduct of underlying trauma issues. Efforts to be punitive with discipline could actually retrigger trauma and escalate behavioral challenges and conflicts. Staff were trained to recognize communication and behavior which could be indicative of trauma, such as "screaming, physical violence, blatant defiance, shutting down and crying." In addressing behavioral concerns through the lens of TICB staff would focus on processing emotions with youth who were displaying indicators of trauma.

Acceptance: The program staff were trained in and practiced a form of "cultural humility" to support acceptance. In short, cultural humility practices focused on engaging families and children with an understanding of the unique challenges they faced. Practitioners approach interactions with compassion so that they can "meet families where they are at" and focused on identifying and building off of family assets (strengths) to support youth.

Community Empowerment: Empowerment efforts in the I Am MBK program were diverse, ranging from skill building activities to working with youth to express themselves through writing, art or music. Empowerment also entailed efforts to strengthen critical thinking skills, fostering the ability to envision and plan for the future. Program youth routinely reported that empowerment efforts improved their self-confidence. 
At a more intensive scale this meant fostering leadership development among older more engaged youth in the program. A "Junior Shepherd" program was established to develop a cohort of youth leaders among the I Am MBK youth. The leadership effort was acknowledged by parents, staff and funders as one of the most effective components of the program. Parents identified the importance of having the emerging African American youth leaders that were local peers for the program's younger children.

Junior Shepard leaders were encouraged to lead activities and mentor younger boys in the program, while also representing the program in engagements with the broader community and community leaders. This included acting as speakers and panelists alongside community leaders, at large community forums discussing issues for African American boys in Columbus. After the program ended, staff reported that Junior Shepherds were still very active within local community building activities.

Reflective Processes: Engaging trauma-informed strategies required constant reflective processes. In the case of I Am MBK this meant constant reflection and program adjustments by staff, institutional partners and funders. Due to the many unanticipated challenges the program's design was constantly in flux as program leaders adjusted strategies to meet needs and better deliver programming.

Programmatic goals were often adjusted after assessing the needs of youth and families. As problems arose in implementation, the program would adjust strategies accordingly. For example, Saturday programs (the most intensive day of weekly programming) did not originally provide transportation. But, after implementation, it became apparent that transportation and other household barriers were a significant roadblock to youth engagement. The program modified its approach by developing transportation solutions and a Saturday morning "wake up" approach (often coming into the home in the morning) assuring youth were able to engage on Saturdays. Saturday program participation rose from $20 \%$ to more than $70 \%$ after making this adjustment.

In another example, program staff realized that food insecurity among youth meant that more substantial meals were needed throughout Saturday programming. As the school week ended, youth lost access to school-provided meals. By Saturday hunger was already a barrier to engagement and learning. Additionally, excess food from program days would be gathered and sent home with youth to feed siblings and other family members during the weekend. These constant shifts in strategy required 
ongoing communication with program funders to articulate why new approaches were constantly needed to meet the needs of youth and families.

\section{How did the TICB approach support health outcomes for youth?}

The primary benefits to participants of the I Am MBK program were improvements in academic outcomes and socio-emotional health. In contrast to the comparison group, I Am MBK youth experienced growth in their academic standing (Figure 3) and increased core academic scores (Figure 4). The Junior Shepherds (the leadership development cohort) had the largest increase in core academic scores. I Am MBK youth also experienced a large decline in school discipline rates (Figure 5).

Socioemotional health scores, measured by the Devereux Students Strengths Assessment (or DESSA), increased for I Am MBK youth (Figure 6). The DESSA is a strengths based behavioral assessment for youth that is founded on resiliency theory for children (LeBuffe et al. 2018 and Naglieri et al. 2012). Parent or caregiver surveys indicated that I Am MBK had a substantial impact on youth and families. More than four out of five parents reported I Am MBK had a positive impact on their child's behavior, self-worth/self-image and optimism (Figure 7). Parents routinely reflected that the program was critical in assisting their families through crises and was life changing for their children.

\section{Learning Circles Core Academics (Active Participants vs. Comparison Group of Inactive Participants)}
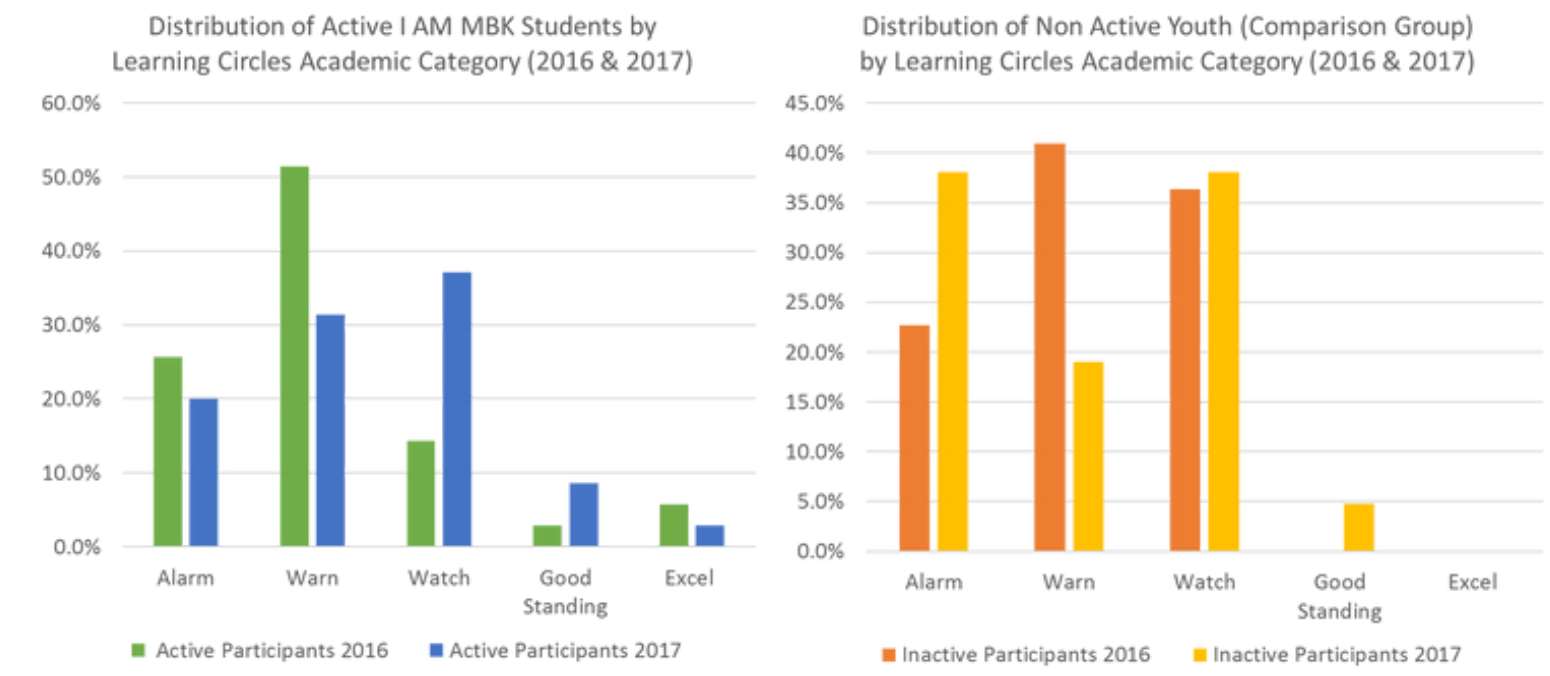

Figure 3. Change over time in Academic Standing for Active I Am MBK Youth (Left) and Comparison Group of Inactive Participants (Right) 
Learning Circles Core Academics Average Scores

(Comparison of Active MBK Youth , Jr Shepherds and Inactive Participants/Comparison Group)

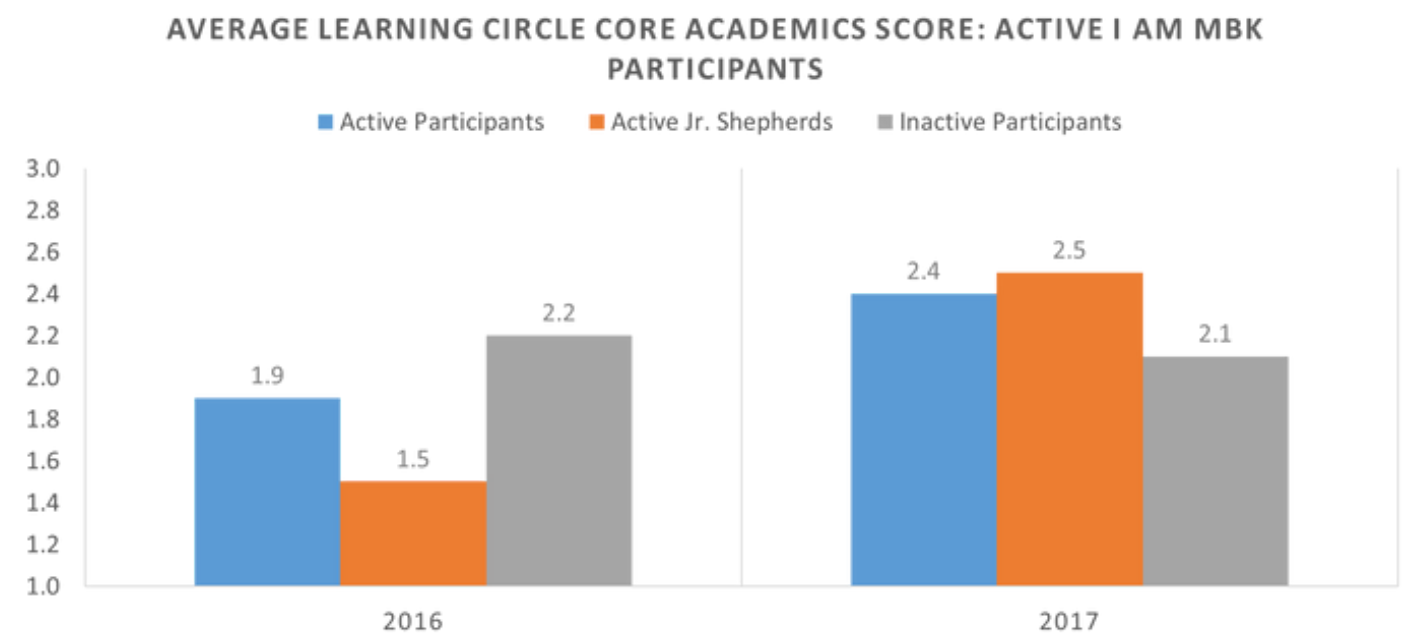

Figure 4. Change over time in Core Academic Rating Score for Active I Am MBK Youth, Jr. Shepherds (Leadership Cohort of I Am MBK Youth) and Comparison Group of Inactive Participants

Learning Circles Discipline Rate Data (Comparing Active MBK Youth to Comparison Group)

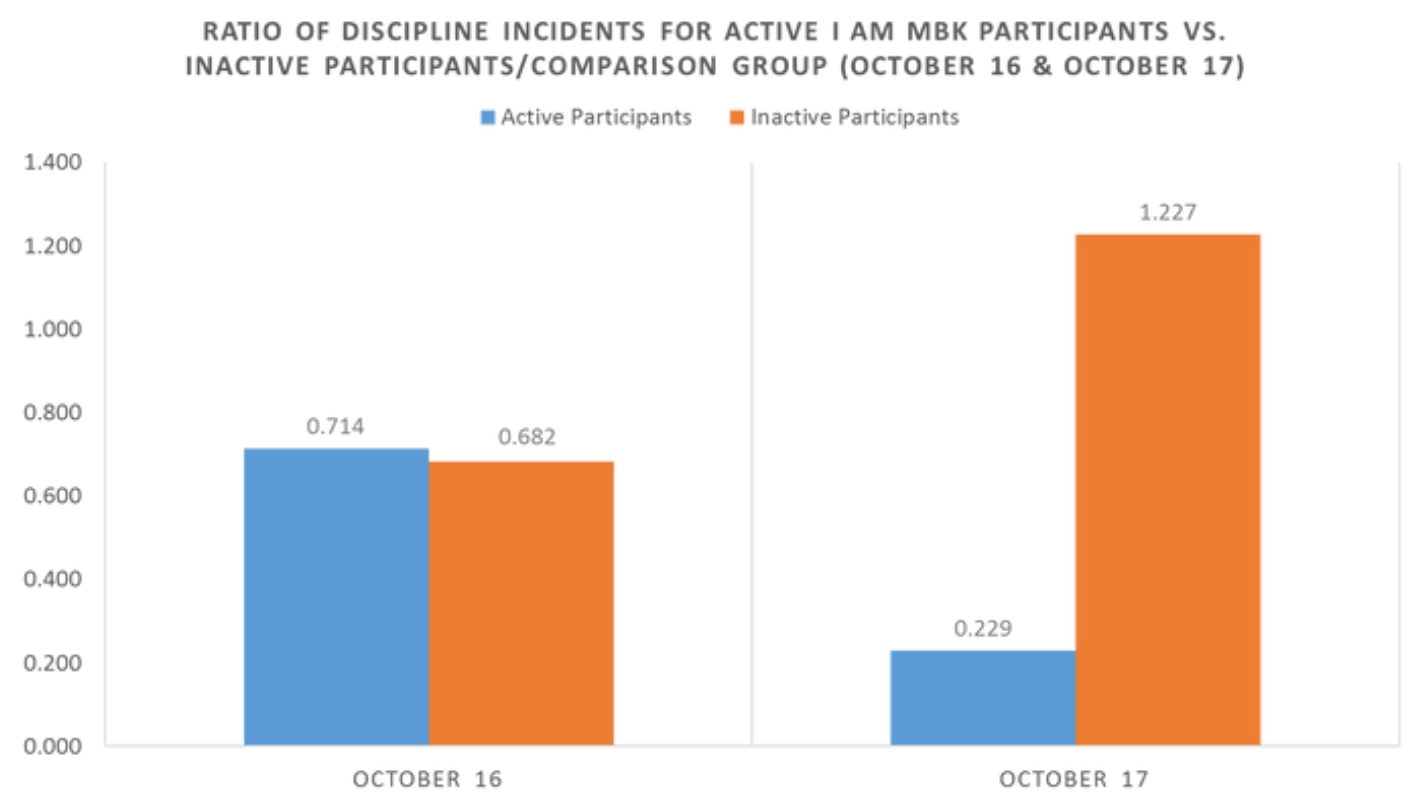

Figure 5. Change over time in School Discipline Rates for Active I Am MBK Youth and Comparison Group of Inactive Participants 
Devereux Student Strengths Assessment (DESSA) - Socioemotional Health Measure

(Trend Over Time for I Am MBK Youth)

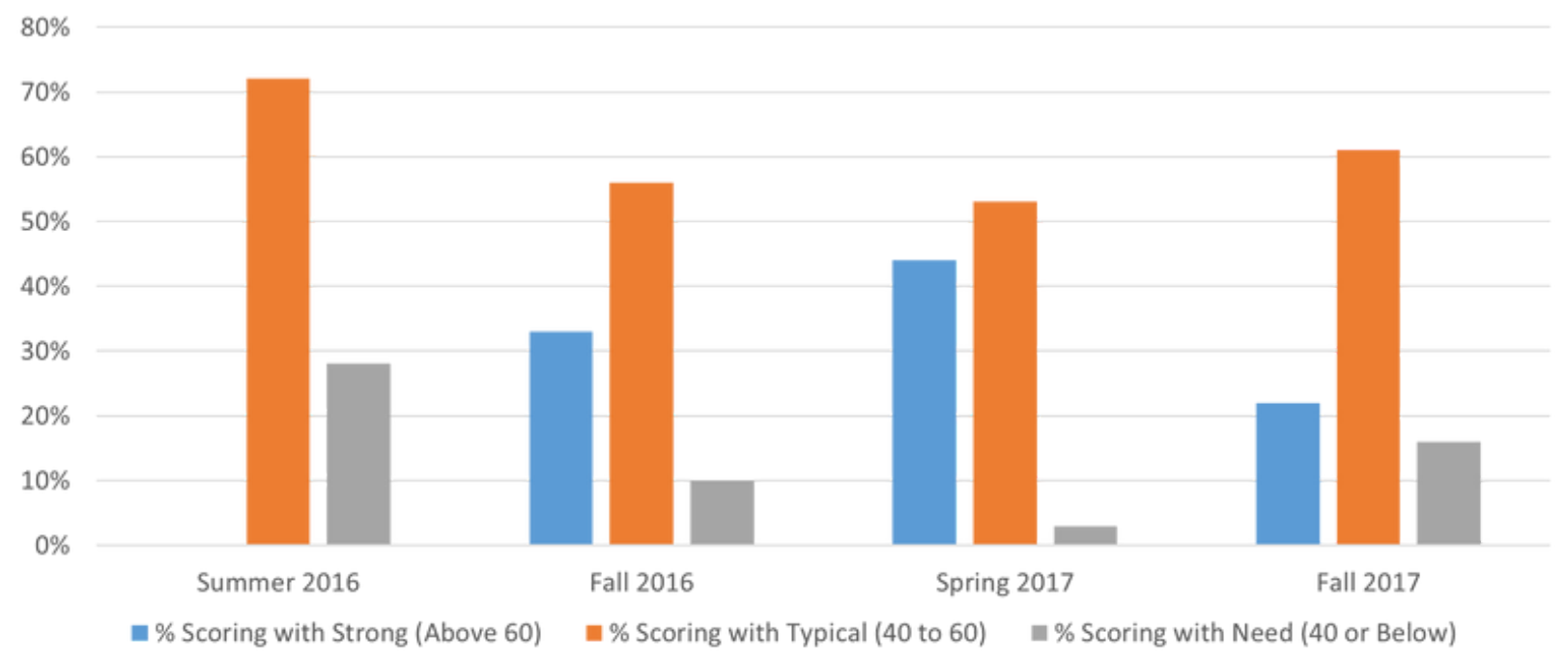

Figure 6. Change over time in Socioemotional Health for I Am MBK Youth

Responses from Parent Survey of I Am MBK Families (35 Families)

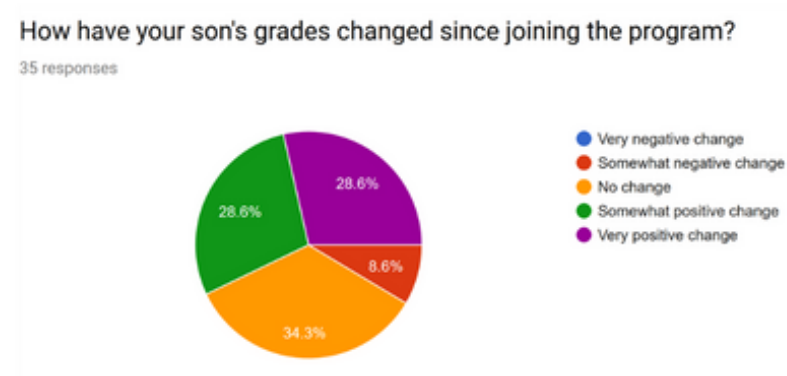

How has your son's behavior changed since joining the program? 35 responses
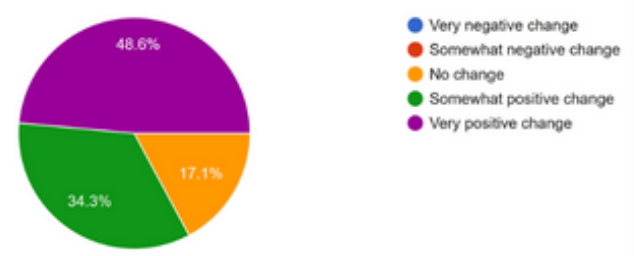

How has your son's self image/self-worth changed since joining the program?

35 responses

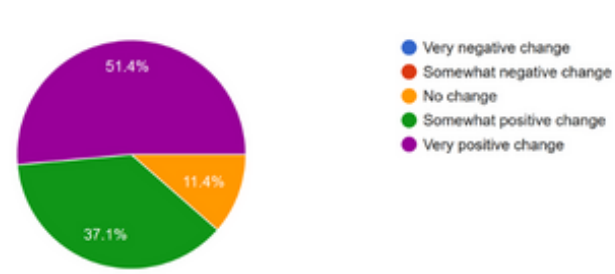

How has being in the program affected your son's optimism? 35 responses

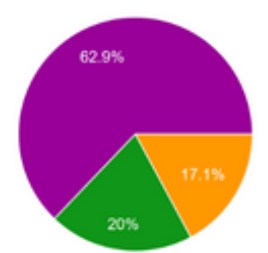

- Very negative change - Somewhat negative change - Somewhat positive change - Very positive change

Figure 7. Parent survey of program impacts on their son's grades, behavior, self-image/self-worth and optimism

The primary emotional health improvements produced by the program included improvement in self-confidence, self-worth and optimism for youth. These direct emotional health impacts were influenced by the leadership development and 
empowerment activities of the TICB model. In addition, stakeholders identified other pathways to emotional health improvement for youth, these included the creation of safe supportive spaces, advocacy within systems, the development of strong social capital between youth and with youth and program staff. Finally, integration of mind/body practices and the experiential learning activities were identified as influential in supporting youth emotional health.

Safe Spaces: Youth indicated the importance of the engagement activities as a "safe space" where they can show vulnerability that they did not feel comfortable expressing with their family, in school or in the neighborhood. I Am MBK youth were often in positions of responsibility in the context of their families, for example, caring for younger siblings or addressing household needs while their caregiver was working. Youth discussed how gendered expectations placed limitations on their ability to express vulnerability and emotion. Creating a cohort of peers and staff who they trusted fostered an environment where they could express emotion without fear or ridicule, rejection or being perceived as weak.

Advocacy: Families within I Am MBK faced many challenging interactions with systems, such as the education system, housing system, judicial system or benefits programs. The program did not originally plan on acting as a family advocate within these system interactions, but over time program leaders found advocacy to be critical for successfully resolving conflict with institutional stakeholders on behalf of youth. Advocacy was also effective in strengthening relationships with participant families. Examples of youth and family advocacy ranged from negotiating discipline issues within school, helping families in tenant landlord disputes, negotiating on behalf of families with the court system and assisting families in accessing benefit programs. Ongoing community advocacy is a critical need in the context of high trauma communities and can be very beneficial to help community members navigate rigid and unforgiving systems and institutions.

Social Capital Development: The success of TICB is dependent on the depth of relationships built among participants. I Am MBK program staff, institutional partners and funders all consistently acknowledged the power of relationships as the primary mechanism which fostered positive outcomes in the program. As described by a program staff member "without the relationship, nothing works." Staff spent hundreds of hours with youth and families through program activities but also through extensive home visits and informal interactions. Parents would call and text the field staff, send 
photos of kids and talk about problems. These interactions fostered emotional intimacy between many of the families and the field staff.

Relationship building required consistency and follow-through from program staff. High trauma communities are often littered with broken promises from elected officials, government agencies and nonprofit organizations. Families had a distrust of many institutions due to these past experiences and staff had to be vigilant in fostering trust building over time through consistency to "build the rapport (that) that gets you through the door." As with other elements of programming, relationship building required intentionality and long-term commitment.

Integrating Mind \& Body Through Wellness: Am MBK youth benefited greatly from physical fitness and wellness activities and experiential opportunities. The I Am MBK program centered several of the program's primary activities on physical fitness and wellness, which also included yoga, meditation and active art therapy. These included physical training with professional trainers but also efforts to integrate various aspects of wellness as a mechanism to alleviate the effects of stress.

Intensive Experiential Activities: Experiential activities were critical to expanding the lived experience of youth and presenting new possibilities as they envisioned their future. Experiential activities were essential to present positive experiences outside of the South Side neighborhood. At the start of the program, very few of the youth had ever left the South Side neighborhood or ventured beyond urban neighborhoods in Columbus. Outdoor activities in the region's Metro Parks, regular trips to the Ohio State University's campus and Central State University (a local Historically Black College/University) and a variety of other ongoing travel opportunities were essential to expanding the worldview of youth.

\section{Challenges: Long term sustainability, staffing and resources}

Several ongoing challenges throughout the implementation of I Am MBK would hinder the program. Sustainability would be compromised by staff burnout and funding challenges. Youth in the I Am MBK program were not the only ones exposed to and impacted by trauma. Exposure to ongoing trauma facing families had a cumulative impact on some staff members. Trauma exposure contributed to staff burnout and turnover.

Additional resource challenges would emerge in regard to coordinating the large number of organizations involved in the program. Effective collaboration required time intensive relationship building between staff and multiple organizations. In some 
circumstances, competition for limited resources created barriers to effective collaboration with some organizations. Trust building is a mediating factor in encouraging cooperative rather than competitive behaviors between nonprofit organizations but can be resource/staff/time intensive to develop (Bunger, 2012).

Stable funding was an ongoing challenge for the I Am MBK program. The program was primarily funded through federal TANF (Temporary Assistance to Needy Families) funds through Franklin County's Department of Jobs and Family Services. TANF funding was somewhat restrictive, requiring additional fundraising to meet many program needs and family needs.

As a highly engaged community intervention, I Am MBK was resource intensive. The program would cost between $\$ 3,000$ and $\$ 5,000$ per year per youth participant. Funders regularly advocated for reducing the per person costs of the program, but costs for staffing, transportation and experiential activities were difficult to reduce. Despite the program's effectiveness, the I Am MBK program eventually would end due to loss of funding after three years.

\section{Challenges: Limitations in addressing larger systemic or structural forms of discrimination}

The structure of the I Am MBK program also was not effective in counteracting larger systemic, structural and institutional barriers impacting youth. These included the impacts of ongoing racial bias within institutions and systems, systemic housing instability, and exposure to ongoing violence within the community.

Research is clear that boys of color face significant explicit and implicit bias, including within educational systems, social service systems and from law enforcement. The model of I Am MBK was effective in creating a safe space for youth within the program but could not counter the institutional discrimination experienced by youth and families. Boys with the I Am MBK program experienced ongoing bias, which can also act as a form of chronic stress or trauma. Program staff were regularly addressing instances of disproportionate discipline within school systems and concerns about bias from program partners within certain experiential sites.

Housing was a systemic challenge facing I Am MBK families and one that undermined the program's effectiveness. Housing instability kept many participating families constantly on the move, impacting the ability to maintain ongoing programming with families. Limited housing resources, particularly short-term financial assistance, was an impediment to keeping families in their homes. While programs to bolster credit 
scores and tenant advocacy were sometimes effective strategies to stabilize families, these efforts were offset by an overall lack of affordable/safe housing units or family financial emergencies.

Exposure to violence was an unrelenting challenge for youth in the program. The program had to utilize violence intervention services from the Columbus Urban League to respond when violence would escalate in the community. Program staff would need to work with youth to help them process what was impacting them in the past week. A "roses and thorns" activity was integrated into weekly gatherings to allow youth an opportunity to discuss both positive and negative experiences from the past week. Youth would often utilize this activity to share and process recent trauma experiences. Ongoing community/police tensions and acts of law enforcement violence would act as an ongoing form of toxic stress in the community. Attempts to utilize the program to foster positive youth and law enforcement interaction were limited and not effective.

\section{Discussion and Conclusion: Expanding our ability to plan for emotional health}

The experience from I Am MBK case aligns with Lyles and Swearingen White's scholarship exploring the impacts of emotion on planning practice. The emotional toll and "burn out" experienced by program staff echoes the challenge of the "emotional paradox" facing planners who engage the public (Lyles \& Swearingen-White, 2019). As described by Lyles and Swearingen-White in Who Cares? Arnstein's Ladder, the Emotional Paradox of Public Engagement, and (Re) imagining Planning as Caring.

"Planners thus contend with contradictory notions of emotion. They must respond to and manage strong emotions from the public while simultaneously tamping down, censoring, or disguising their own feelings. The paradox generates tension as planners navigate complicated relationships characterized by unpredictable and sometimes precarious emotions, especially when planning exposes long legacies and current realities of conflict, trauma, and oppression in communities." (Lyles \& Swearingen-White, 2019, pg. 288).

Lyles and Swearingen White propose engaging emotion in the profession through leadership development, cultural humility practices and cultivating compassion. TICB directly embraces the use of cultural humility espoused by Lyles and Swearingen White. Lyles and Swearingen White's emphasis on recognizing the emotional impacts of engagement on practitioners, remedies a shortcoming in the TICB model. 
For example, the I Am MBK program was focused on the emotional experiences of residents, but initially little attention was paid to the emotional toll on program staff. Ironically, a program designed to be very cognizant of the emotional dynamics impacting the community, ignored the impacts of emotion on the program practitioners. Eventually, mechanisms for helping staff set boundaries and reflect upon/process trauma were needed to stabilize the program staffing. Recognition of the effects of trauma on the community, must also require a recognition of exposure to trauma experienced by practitioners and mechanisms to process that experience.

\section{Can we develop a comprehensive model of planning to support emotional health for youth in high trauma environments?}

The scholarly discourse and models for planning practice to address trauma are still emergent. The various models (Therapeutic Planning, Trauma Informed Community Building, Restorative Healing) each have strengths and weaknesses. By engaging models comprehensively, the field can develop a model for planning in high trauma communities, and present approaches for both addressing historical trauma and contemporary environmental stressors which foster trauma. A comprehensive model should outline ideal methods of engagement but also provide a clear view of what qualities are needed in practitioners. Most importantly, the model could allow for the possibility of creating systemic political change. Table 5 presents a synthesis of this literature to introduce an example of what a comprehensive model could entail. The importance of engaging with emotion and trauma in planning necessitates further development of a robust model of practice.

\section{Table 5}

Example of a comprehensive model of planning

for high trauma communities.

\section{Community Context:}

Planning for communities who have experienced past historical trauma, structural discrimination and contemporary environmental trauma.

Working within communities where the "depth and breadth" of community needs can overwhelm community development practice. 


\section{Type of Engagement 1: Reconciliation \& Healing}

(Sandercock 2000; Sandercock 2004;

Sandercock and Attila 2014; Erfan, 2017)

\section{Type of Engagement 2: Reforming ongoing} planning practice (Weinstein et al. 2014;

Falkenburger et al. 2018)
Development of specialized engagement processes to engage, confront and process past historical trauma and structural discrimination. Emphasis on connecting past to present.
Reforming traditional ongoing community development practice to be trauma informed. Emphasis on targeting influential community stressors while fostering community resiliency. Creation of safe community spaces. Foster leadership development and other forms of community empowerment.
Attributes for Planners/Practitioners (Lyles and Swearingen White, 2019)
Emphasis on fostering cultural humility, planning leadership and cultivation of compassion (Selfawareness, awareness of others, empowerment through relationships, self-management, working with difference, extending compassion).

Planner as advocate for community members within their interactions with existing government and institutional systems. Recognition that community members will face implicit and explicit bias in navigating systems.

Planner seeks to support broader institutional and systems change by adhering to Schweitzer's 3 professional obligations.

1) Build collective understanding;

2) Produce institutional reform;

3) Foster political transformation.

By integrating concepts from TICB, therapeutic planning can deepen its analysis to articulate both the role of historic trauma and contemporary trauma in communities. TICB could compliment traditional therapeutic planning by placing emphasis on remedying these contemporary stressors (which can be dynamic and shifting). TICB can be improved by being more attentive to the emotional needs of youth and the impact of Adverse Childhood Experiences (ACE's). 
Both therapeutic planning and TICB are informed by communicative action.

Therapeutic planning places emphasis on structuring a specific communicative process to engage historical community trauma. TICB places more emphasis on traumainformed community engagement strategies to work with a community on a day to day basis. The intersection of TICB and therapeutic planning could provide a model which enables planners to lead special community engagement activities focused on historical trauma while also providing strategies for on-going community engagement which is trauma informed. These trauma-informed practices could be utilized by multiple disciplines or sectors working within a community.

TICB is a model that originated from the field of public health and it emphasizes the mental and physical health impacts of trauma and chronic stress. Planning's relationship with the field of public health is long standing, but much of that history has emphasized the built environment and physical health relationship (Kochtitzky et al. 2006). Planning practice has paid less attention to issues of mental health. Therapeutic planning should utilize the evidence base that drives trauma informed public health practice to support community engagement activities which directly address forms of community trauma. Therapeutic planning can be critiqued as being too steeped in emotion, but the evidence is clear that emotion directly impacts community health and prevalence of disease (Danese and McEwen 2012 \& Mariotti, 2015).

\section{Can we align planning for emotion with systems level or structural reform?}

TICB is rooted in public health and many of the critiques of public health practice apply to trauma informed practice. Traditional public health practice places more emphasis on the individual than larger structural challenges. Even in the context of addressing social determinants of health, interventions tend to focus more on health promotion, behavioral change or health care access than impacting deeper structural change (Baum \& Fisher, 2014).

The deficiency of TICB to robustly address structural conditions is evident in many of the challenges experienced in the I Am MBK case. Chronic housing instability plagued the I Am MBK families, and individualized actions such as tenant advocacy could not address larger systemic housing challenges emanating from a shortage of affordable units. While I Am MBK fostered resiliency in youth, the program model could not impact the various forms of structural and institutional discrimination facing I Am MBK youth. 
Planning for emotion requires working at multiple scales, the individual, the community and within systems. Our existing discourse on planning for emotion, such as therapeutic planning or TICB, could be strengthened by integrating Lisa Schweitzer's model of "restorative healing” (Schweitzer, 2014). Schweitzer's three professional obligations within restorative healing (build collective understanding, seek institutional reform and transform the broader political community) provide insight into the limitations of the TICB model. The I Am MBK case met Schweitzer's first obligation and did seek to build collective understanding around the challenges and solutions needed for the program's families. Public forums and presentations to multiple institutional stakeholders, public sector officials and funders were held to share the experiences of I Am MBK youth.

The program failed at meeting Schweitzer's second and third obligations. No institutional reforms were produced from the I Am MBK program nor was there a transformation of the broader political community. While the program improved mental health outcomes for youth and fostered resiliency, it did not have a deeper impact in dismantling structural forms of discrimination in the community. Future utilization of the TICB model will require a broader commitment to all three professional obligations to foster restorative healing and the transformation of structural conditions. Trauma-informed practice can support resiliency but without efforts to foster institutional reforms and larger political change, it will be limited in its ability to dismantle structural forms of discrimination which continue to harm marginalized communities.

\section{References}

Acevedo-Garcia, Dolores, Nancy McArdle, Erin F. Hardy, Unda Ioana Crisan, Bethany Romano, David Norris, Mikyung Baek, and Jason Reece. "The Child Opportunity Index: Improving Collaboration between Community Development and Public Health." Health Affairs (Project Hope) 33, no. 11 (November 2014): 1948-57. https://doi.org/10.1377/hlthaff.2014.0679.

American Academy of Pediatrics. "Adverse Childhood Experiences and the Lifelong Consequences of Trauma." (2014). Traumaguide at www.aap.org/traumaguide

Annie E. Casey Foundation. "22\% of U.S. kids have had multiple adverse experiences." Kids Count News. (2018). 
Arnstein, S. R. "A ladder of citizen participation." Journal of the American Institute of Planners, 35, 216-224. (1969).

Aviles, Ann M., and Nicole Grigalunas. “'Project awareness:' Fostering Social Justice Youth Development to Counter Youth Experiences of Housing Instability, Trauma and Injustice." Children and Youth Services Review 84 (January 2018): 229-38.

https://doi.org/10.1016/j.childyouth.2017.12.013.

Baum, Fran, and Matthew Fisher. "Why Behavioural Health Promotion Endures despite Its Failure to Reduce Health Inequities." Sociology of Health \& Illness 36, no. 2 (February 1, 2014): 213-25. https://doi.org/10.1111/1467-9566.12112.

Baum, Howell. "Planning with Half a Mind: Why Planners Resist Emotion." Planning Theory \& Practice 16, no. 4 (October 2, 2015): 498-516.

https://doi.org/10.1080/14649357.2015.1071870.

Birch, Eugenie. "Cities, People, and Processes as Planning Case Studies." The Oxford Handbook of Urban Planning, January 1, 2012. https://doi.org/10.1093/oxfordhb/9780195374995.013.0014.

Blair, Alexandra. "How Community Resources Mitigate the Association between Household Poverty and the Incidence of Adverse Childhood Experiences." International Journal of Public Health, May 28, 2019.

Braun, Virginia, and Victoria Clarke. "Using Thematic Analysis in Psychology." Qualitative Research in Psychology 3, no. 2 (January 1, 2006): 77-101. https://doi.org/10.1191/1478088706qp063oa.

Bulanda, Jeffrey, and Trisha Byro Johnson. "A Trauma-Informed Model for Empowerment Programs Targeting Vulnerable Youth." Child and Adolescent Social Work Journal 33, no. 4 (August 2016): 303-12. https://doi.org/10.1007/s10560-0150427-z.

Bunger, Alicia C. "Administrative Coordination in Nonprofit Human Service Delivery Networks: The Role of Competition and Trust." Nonprofit and Voluntary Sector Quarterly 42, no. 6 (December 2013): 1155-75. doi:10.1177/0899764012451369.

Center for Disease Control. (2020, January 28). The Social-Ecological Model: A Framework for Prevention |Violence Prevention|Injury Center|CDC. Retrieved August 27, 2020, from https://www.cdc.gov/violenceprevention/publichealthissue/socialecologicalmodel.htmlCampbell, Scott. "Case Studies in Planning: Comparative 
Advantages and the Problem of Generalization." Urban and Regional Research Collaborative. University of Michigan. URRC 02-07. (2003).

Chetty, S, A R Friedman, K Taravosh-Lahn, E D Kirby, C Mirescu, F Guo, D Krupik, et al. "Stress and Glucocorticoids Promote Oligodendrogenesis in the Adult Hippocampus.” Molecular Psychiatry 19 (February 11, 2014): 1275.

Danese, Andrea, and Bruce S. McEwen. "Adverse Childhood Experiences, Allostasis, Allostatic Load, and Age-Related Disease." Allostasis and Allostatic Load 106, no. 1 (April 12, 2012): 29-39. https://doi.org/10.1016/j.physbeh.2011.08.019.

Danielson, Ramona, and Divya Saxena. "Connecting Adverse Childhood Experiences and Community Health to Promote Health Equity." Social and Personality Psychology Compass, no. 7 (2019). https://doi.org/10.1111/spc3.12486.

Denzin, NK. Sociological Methods. New York: McGraw-Hill. 1978.

Dumont, M., and M. A. Provost. "Resilience in Adolescents: Protective Role of Social Support, Coping Strategies, Self-Esteem, and Social Activities on Experience of Stress and Depression." Journal of Youth and Adolescence 28, no. 3 (June 1999): 343-63. https://doi.org/10.1023/A:1021637011732.

Erfan, Aftab. "Confronting Collective Traumas: An Exploration of Therapeutic Planning." Planning Theory \& Practice 18, no. 1 (January 2, 2017): 34-50. https://doi.org/10.1080/14649357.2016.1249909.

Falkenburger, Elsa., Arena, Olivia., and Wolin, Jessica. "Trauma-Informed Community Building and Engagement. The Urban Institute. Metropolitan Housing and Communities Policy Center. (April 2018).

Forester, J. The deliberative practitioner: Encouraging participatory planning processes. Boston, MA: MIT Press. 1999

Flyvbjerg, Bent. "Five Misunderstandings About Case-Study Research.” Qualitative Inquiry 12, no. 2 (April 1, 2006): 219-45. https://doi.org/10.1177/1077800405284363.

Gentner, Maura B., and Mary L. O’Connor Leppert. “Environmental Influences on Health and Development: Nutrition, Substance Exposure, and Adverse Childhood Experiences." Developmental Medicine and Child Neurology 61, no. 9 (September 2019): 1008-+. https://doi.org/10.1111/dmcn.14149. 
Gordon, Danielle., Rebanal, David., Simon-Ortiz, Sophie., Tokunaga, Jessica., and Wolin, Jessica. "Trauma Informed Community Building Evaluation: A Formative Evaluation of the TICB Model and its Implementation in Potrero Hill. Hope SF Learning Center at the Health Equity Institute at San Francisco State University. (2015).

Griggs, Stephanie, Hilary H. Ratner, John H. Hannigan, Virginia Delaney-Black, and Lisa M. Chiodo. "Violence Exposure, Conflict, and Health Outcomes in Inner-City African American Adolescents." Nursing Forum, n.d. https://doi.org/10.1111/nuf.12365.

Harden, Troy, Thomas Kenemore, Kimberly Mann, Michael Edwards, Christine List, and Karen Jean Martinson. "The Truth N' Trauma Project: Addressing Community Violence Through a Youth-Led, Trauma-Informed and Restorative Framework." Child and Adolescent Social Work Journal 32, no. 1 (February 2015): 65-79. https://doi.org/10.1007/s10560-014-0366-0.

Heard-Garris, N. J., M. Cale, L. Camaj, M. C. Hamati, and T. P. Dominguez.

“Transmitting Trauma: A Systematic Review of Vicarious Racism and Child Health." Social Science \& Medicine 199 (February 2018): 230-40.

https://doi.org/10.1016/j.socscimed.2017.04.018.

Hecht, Amelie A., Erin Biehl, Sarah Buzogany, and Roni A. Neff. “Using a TraumaInformed Policy Approach to Create a Resilient Urban Food System." Public Health Nutrition 21, no. 10 (July 2018): 1961-70. https://doi.org/10.1017/S1368980018000198.

Herrenkohl, Todd I., Sunghyun Hong, and Bethany Verbrugge. "Trauma-Informed Programs Based in Schools Linking Concepts to Practices and Assessing the Evidence." American Journal of Community Psychology, n.d. https://doi.org/10.1002/ajcp.12362.

Hughes, Karen, Mark A Bellis, Katherine A Hardcastle, Dinesh Sethi, Alexander Butchart, Christopher Mikton, Lisa Jones, and Michael P Dunne. "The Effect of Multiple Adverse Childhood Experiences on Health: A Systematic Review and MetaAnalysis." The Lancet Public Health 2, no. 8 (August 1, 2017): e356-66. https://doi.org/10.1016/S2468-2667(17)30118-4.

Jackson, James S., Katherine M. Knight, and Jane A. Rafferty. "Race and Unhealthy Behaviors: Chronic Stress, the HPA Axis, and Physical and Mental Health Disparities Over the Life Course." American Journal of Public Health 100, no. 5 (May 1, 2010): 933-39. https://doi.org/10.2105/AJPH.2008.143446. 
Kelleher, Kelly \& Edgar, John. “A Decade of Health Homes.” Pediatrics Nationwide. (March 5, 2020). Accessible at: https://pediatricsnationwide.org/2020/03/05/a-decadeof-healthy-homes/? fbclid=IwAR16j8vC9JFaWWfS6For6iWB78EwgPINcAxctUbBl3lWmlo0dN-Rl4P4S8Q.

Kelleher, Kelly, Jason Reece, and Megan Sandel. "The Healthy Neighborhood, Healthy Families Initiative.” Pediatrics 142, no. 3 (September 1, 2018): e20180261. https://doi.org/10.1542/peds.2018-0261.

Kochtitzky, Christopher, Howard Frumkin, R Rodriguez, AL Dannenberg, J Rayman, K Rose, R Gillig, and T Kanter. “Urban Planning and Public Health at CDC.” MMWR. Morbidity and Mortality Weekly Report 55 Suppl 2 (January 1, 2007): 34-38.

LeBuffe, Paul A., Valerie B. Shapiro, and Jennifer L. Robitaille. "The Devereux Student Strengths Assessment (DESSA) Comprehensive System: Screening, Assessing, Planning, and Monitoring." Social-Emotional Assessment to Guide Educational Practice 55 (March 1, 2018): 62-70. https://doi.org/10.1016/j.appdev.2017.05.002.

Lee, Jocelyn R. Smith, and Michael A. Robinson. “'That's My Number One Fear in Life. It's the Police': Examining Young Black Men's Exposures to Trauma and Loss Resulting From Police Violence and Police Killings.” Journal of Black Psychology 45, no. 3 (April 2019): 143-84. https://doi.org/10.1177/0095798419865152.

Lincoln, Y. S., \& Guba, E. G. "But is it rigorous? Trustworthiness and authenticity in naturalistic evaluation." New Directions for Program Evaluation, 1986:30, 73-84. (September 06, 1986).

Lincoln, Y. S., \& Guba, E. G. Naturalistic inquiry. Beverly Hills, Calif: Sage Publications. (1985).

Lubit, Roy. Rovine, Deborah., Defrancisci, Lea., and Eth, Spencer. "Impact of Trauma on Children." Journal of Psychiatric Practice® 9, no. 2 (2003).

https://journals.lww.com/practicalpsychiatry/Fulltext/2003/03000/Impact_of_Trauma_on _Children.4.aspx.

Lyles, Ward, and Stacey Swearingen White. "Who Cares?” Journal of the American Planning Association 85, no. 3 (July 3, 2019): 287-300.

https://doi.org/10.1080/01944363.2019.1612268.

Magruder, Kathryn M, Katie A McLaughlin, and Diane L Elmore Borbon. "Trauma Is a Public Health Issue.” European Journal of Psychotraumatology 8, no. 1 (October 9, 
2017): 1375338-1375338. https://doi.org/10.1080/20008198.2017.1375338.

Marin, Marie-France, Catherine Lord, Julie Andrews, Robert-Paul Juster, Shireen Sindi, Geneviève Arsenault-Lapierre, Alexandra J. Fiocco, and Sonia J. Lupien. "Chronic Stress, Cognitive Functioning and Mental Health." Memory Impairment and Disease 96, no. 4 (November 1, 2011): 583-95. https://doi.org/10.1016/j.nlm.2011.02.016.

Mariotti, Agnese. "The Effects of Chronic Stress on Health: New Insights into the Molecular Mechanisms of Brain-Body Communication.” Future Science OA 1, no. 3 (November 1, 2015): FSO23-FSO23. https://doi.org/10.4155/fso.15.21.

Marris, P. Loss and change. London: Routledge \& Kegan Paul. 1974.

Mayberry, Lindsay Satterwhite, Marybeth Shinn, Jessica Gibbons Benton, and Jasmine Wise. "Families Experiencing Housing Instability: The Effects of Housing Programs on Family Routines and Rituals." American Journal of Orthopsychiatry 84, no. 1 (2014): 95-109. https://doi.org/10.1037/h0098946.

McGee, Zina T., Kyle Logan, Joseph Samuel, and Tandeka Nunn. “A Multivariate Analysis of Gun Violence among Urban Youth: The Impact of Direct Victimization, Indirect Victimization, and Victimization among Peers.” Edited by Jamie Halsall. Cogent Social Sciences 3, no. 1 (January 1, 2017): 1328772. https://doi.org/10.1080/23311886.2017.1328772.

Mersky, J P, J Topitzes, and A J Reynolds. "Impacts of Adverse Childhood Experiences on Health, Mental Health, and Substance Use in Early Adulthood: A Cohort Study of an Urban, Minority Sample in the U.S." Child Abuse \& Neglect 37, no. 11 (November 2013): 917-25. https://doi.org/10.1016/j.chiabu.2013.07.011.

Mersky, Joshua P., James Topitzes, and Linda Britz. "Promoting Evidence-Based, Trauma-Informed Social Work Practice.” Journal of Social Work Education, n.d. https://doi.org/10.1080/10437797.2019.1627261.

Morris, Gerwyn, Michael Berk, Michael Maes, Andre F. Carvalho, and Basant K. Puri. "Socioeconomic Deprivation, Adverse Childhood Experiences and Medical Disorders in Adulthood: Mechanisms and Associations." Molecular Neurobiology 56, no. 8 (August 2019): 5866-90. https://doi.org/10.1007/s12035-019-1498-1.

Morsy, Leila., and Rothstein, Richard. “Toxic stress and children's outcomes.” Research Report. Economic Policy Institute. (May 2019). 
Naglieri, Jack A., Paul A. LeBuffe, and Katherine M. Ross. "Measuring resilience in children: From theory to practice." In Handbook of resilience in children, pp. 241-259. Springer, Boston, MA, 2013.

Neufeld, Susan. “Community Building Despite Trauma.” Shelterforce: The Voice of Community Development. (May 4, 2016). Accessible at:

https://shelterforce.org/2016/05/04/community-building-despite-trauma/. Last accessed $2 / 21 / 20$.

Patton, M. Q. Qualitative Research \& Evaluation Methods: Integrative Theory and Practice. SAGE Publications. 2014.

Rajan, Sonali, Charles C. Branas, Dawn Myers, and Nina Agrawal. "Youth Exposure to Violence Involving a Gun: Evidence for Adverse Childhood Experience Classification." Journal of Behavioral Medicine 42, no. 4 (August 2019): 646-57. https://doi.org/10.1007/s10865-019-00053-0.

Ramsden, Edmund, and Smith, Matthew. "Remembering the West End: Social Science, Mental Health and the American Urban Environment, 1939-1968." Urban History 45, no. 1 (2018): 128-49. https://doi.org/10.1017/S0963926817000025.

Reece, Jason, and Holley, Kip. "More Than My Brothers Keeper: Interim Evaluation Report." The Kirwan Institute for the Study of Race \& Ethnicity, The Ohio State University. 2014.

Reece, Jason. “More Than My Brothers Keeper: Evaluation Report. The Kirwan Institute for the Study of Race \& Ethnicity, The Ohio State University. 2015.

Reece, Jason, and Kenitzer, Zach. "I Am My Brothers Keeper Program Evaluation. City \& Regional Planning Section Knowlton School of Architecture \& The Kirwan Institute for the Study of Race \& Ethnicity, The Ohio State University. 2017.

Russell, Georgina, and Stafford Lightman. “The Human Stress Response.” Nature Reviews Endocrinology 15, no. 9 (September 2019): 525-34.

https://doi.org/10.1038/s41574-019-0228-0.

Sandercock, Leonie. “Towards a Planning Imagination for the 21st Century.” Journal of the American Planning Association 70, no. 2 (June 30, 2004): 133-41. https://doi.org/10.1080/01944360408976368. 
Sandercock, Leonie. "When Strangers Become Neighbours: Managing Cities of Difference." Planning Theory \& Practice 1, no. 1 (January 1, 2000): 13-30. https://doi.org/10.1080/14649350050135176.

Sandercock, Leonie, and Attili, Giovanni. "Changing the Lens: Film as Action Research and Therapeutic Planning Practice." Journal of Planning Education and Research 34, no. 1 (January 16, 2014): 19-29. https://doi.org/10.1177/0739456X13516499.

Schweitzer, Lisa. "Restorative Planning Ethics: The Therapeutic Imagination and Planning in Public Institutions." Planning Theory 15, no. 2 (June 29, 2014): 130-44. https://doi.org/10.1177/1473095214539620.

Shannon Sullivan. "Inheriting Racist Disparities in Health: Epigenetics and the Transgenerational Effects of White Racism," no. 2 (2013): 190.

Stern, Kaija R., and Zaneta M. Thayer. "Adversity in Childhood and Young Adulthood Predicts Young Adult Depression." International Journal of Public Health 64, no. 7 (September 2019): 1069-74. https://doi.org/10.1007/s00038-019-01273-6.

Sullivan, Kelly, Haresh Rochani, Li-Ting Huang, Diane K. Donley, and Jian Zhang. "Adverse Childhood Experiences Affect Sleep Duration for up to 50 Years Later." Sleep 42, no. 7 (July 2019): UNSP zsz087. https://doi.org/10.1093/sleep/zsz087.

Tough, Paul. How children succeed: Grit, curiosity, and the hidden power of character. Houghton Mifflin Harcourt. (2012)

University of Wisconsin. "Trauma-informed approaches to community building." What Works for Health: Policies and Programs to Improve Wisconsin's Health. (2019).

Van der Kolk, Bessel A. Psychological Trauma. American Psychiatric Pub, 2003.

Weinstein, Emily. Wolin, Jessica., and Rose, Sharon. "Trauma Informed Community Building. A Model for Strengthening Community Trauma Affected Neighborhoods." BRIDGE Housing Corporation and the Health Equity Institute of San Francisco State University. (2014).

Whiteside-Mansell, Leanne, Lorraine McKelvey, Jennifer Saccente, and James P. Selig. "Adverse Childhood Experiences of Urban and Rural Preschool Children in Poverty." International Journal of Environmental Research and Public Health 16, no. 14 (July 2, 2019): 2623. https://doi.org/10.3390/ijerph16142623. 
Yang, Mai See, and Donald Hedeker. "A Life-Span Approach to Examining Older Vulnerable Population's Subjective Well-Being: The Role of Adversity and Trauma." Aging \& Mental Health, n.d. https://doi.org/10.1080/13607863.2019.1652245.

Yin., Robert K., Case Study Research Design and Methods (5th ed.). Thousand Oaks, CA: Sage. 2014. 